\title{
Geometric non-linear analysis of composite laminated plates using higher order finite strip element
}

\begin{abstract}
A finite strip method for geometric non-linear static analysis based on the tangential stiffness matrix has been developed using the new concept of polynomial finite strip elements, with Reissner (higher order shear deformable element) plate-bending theory for composite plates. A finite strip analysis programming package, which is capable of performing non-linear analysis for composite flat panels, has also been developed with Reissner plate bending element. Good agreement with the finite element results has been observed through various test cases, confirming the accuracy and reliability of the new developed finite strip method.
\end{abstract}

Keyword: Finite strip methods; Non-linear static analysis; Reissner plate bending theory; Tangential stiffness matrix 